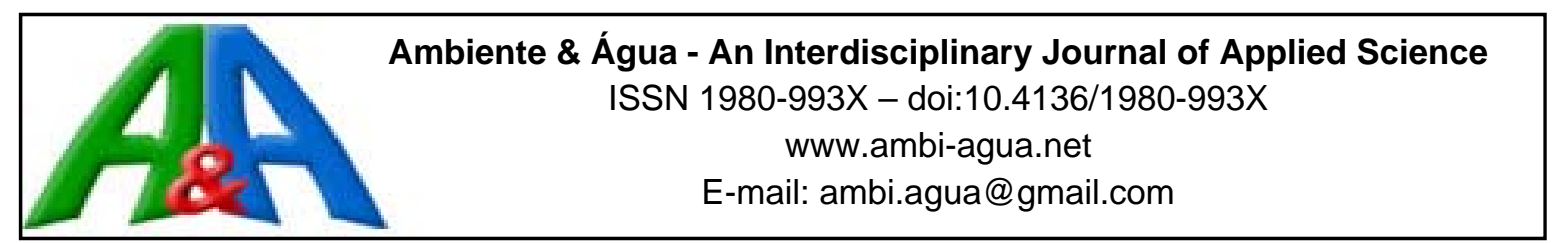

\title{
Remoção de microcistina-LR da Microcystis aeruginosa utilizando bagaço de cana-de-açúcar in natura e carvão ativado
}

\author{
doi:10.4136/ambi-agua.1785
}

Received: 15 Oct. 2015; Accepted: 04 Dec. 2015

\author{
Aline Rafaela de Almeida ${ }^{1 *}$; Fernando Hermes Passig'; Thomaz Aurélio Pagioro ${ }^{1}$, \\ Priscila Tiemi Higuti do Nascimento"; \\ Karina Querne de Carvalho ${ }^{2}$

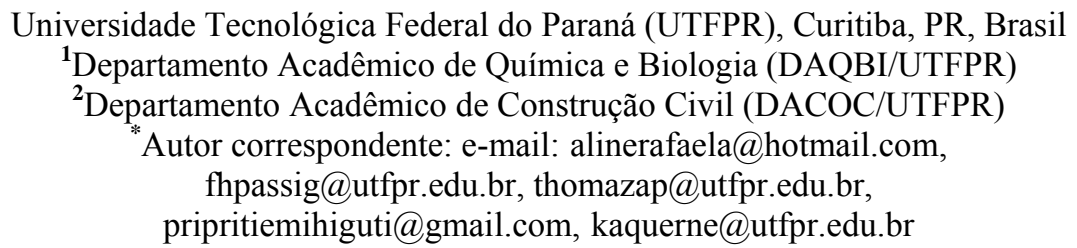

\section{RESUMO}

Microcistina-LR é um tipo de toxina liberada pela cianobactéria Microcystis aeruginosa encontrada em mananciais de água usados para abastecimento humano que pode causar doenças e até mesmo a mortandade do homem se não for totalmente removida no tratamento convencional da água. A retenção desta toxina é muitas vezes realizada através do processo de adsorção em carvão ativado nas estações de tratamento de água. Neste estudo foi avaliada a utilização do bagaço de cana-de-açúcar in natura como bioadsorvente em comparação ao carvão ativado na retenção da microcistina-LR. Primeiramente foi caracterizado o bioadsorvente e o carvão ativado em função de suas características físicas e químicas, e posteriormente foram realizados ensaios de adsorção. O desempenho da adsorção foi avaliado pela eficiência da retenção da toxina e pela capacidade máxima adsortiva. As eficiências médias de retenção da toxina no carvão ativado resultaram em 65,25; 41,74 e 11,75\%; e de 24,15; 18,92 e 12,27\% no bagaço de cana-de-açúcar para as concentrações de 2,36, 3,33 e $3,83 \mu \mathrm{g} \mathrm{L}{ }^{-1}$, respectivamente. $\mathrm{O}$ bioadsorvente apresentou eficiência de remoção da toxina similar àquela observada no carvão ativado para a concentração de $3,83 \mu \mathrm{g} \mathrm{L}^{-1}$. A capacidade máxima adsortiva obtida com o melhor ajuste linear para isoterma de Freundlich, foi de $6047,84 \mu \mathrm{g} \mathrm{g}^{-1}$ (concentração de toxina de 3,83 $\mu \mathrm{g} \mathrm{L}^{-1}$ ) para o bagaço de cana-de-açúcar e de $338,61 \mu \mathrm{g} \mathrm{g}^{-1}$ (concentração de toxina de $2,36 \mu \mathrm{g} \mathrm{L}^{-1}$ ) para o carvão ativado.

Palavras-chave: adsorção, isoterma de Freundlich, isoterma de Langmuir.

\section{Microcystin-LR removal from Microcystis aeruginosa using in natura sugarcane bagasse and activated carbon}

\section{ABSTRACT}

Microcystin-LR is a type of toxin released by the Microcystis aeruginosa cyanobacteria found in water sources used for human consumption. It can cause illness and even death if not completely removed in conventional water treatment. The retention of this toxin is often 
accomplished by the adsorption process in activated carbon in water treatment plants. In this study, a comparison was made between the retention of microcystin-LR by activated carbon and by sugarcane bagasse in natura applied as a bio-adsorbent. Adsorption experiments were performed after the physical and chemical properties of the bio adsorbent and the activated carbon were characterized. The adsorption performance was evaluated by the toxin removal efficiency and the maximum adsorption capacity. Average removal efficiencies of the toxin resulted in $65.25 ; 41.74$ and $11.75 \%$ for the activated carbon and $24.15 ; 18.92$ and $12.27 \%$ for the sugarcane bagasse for concentrations of $2.36,3.33$ and $3.83 \mu \mathrm{g} \mathrm{L}^{-1}$, respectively. The bio adsorbent presented removal efficiency for the toxin similar to that observed in the activated carbon for the concentration of $3.83 \mu \mathrm{g} \mathrm{L} \mathrm{L}^{-1}$. Maximum adsorption capacity obtained with better linear adjustment to the Freundlich isotherm was $6,047.84 \mu \mathrm{g} \mathrm{g}^{-1}$ (toxin concentration of $3.83 \mu \mathrm{g} \mathrm{L}^{-1}$ ) for sugarcane bagasse and $338.61 \mu \mathrm{g} \mathrm{g}^{-1}$ (toxin concentration of $2.36 \mu \mathrm{g} \mathrm{L}^{-1}$ ) for activated carbon.

Keywords: adsorption, Freundlich isotherm, Langmuir isotherm.

\section{INTRODUÇÃO}

A microcistina-LR é um tipo de toxina hepatotóxica produzida pela cianobactéria Microcystis aeruginosa, uma das mais frequentemente encontradas em mananciais de abastecimento de água para consumo humano. O valor máximo permitido desta toxina na água potável é de $1,0 \mu \mathrm{g} \mathrm{L}^{-1}$, conforme estabelecido na Portaria 2914/2011 do Ministério da Saúde (Brasil, 2011).

A presença de cianotoxinas em mananciais ocorre principalmente devido à aceleração do processo de eutrofização, comumente relacionada ao enriquecimento artificial dos ecossistemas aquáticos pelo excesso de compostos fosfatados e nitrogenados de origem sanitária e industrial de descargas sem tratamento prévio, e das regiões agricultáveis, devido ao uso intensivo de fertilizantes (Azevedo et al., 2002).

A quantidade excessiva destes nutrientes, atrelada às condições climáticas da região, favorece a floração de cianobactérias em águas de mananciais. O maior problema está no fato de que algumas espécies ocorrentes destas florações produzem e liberam toxinas para o ambiente no momento de senescência ou lise celular, o que consequentemente acarreta em danos à saúde da população (Belisário et al., 2011).

$\mathrm{O}$ caso mais grave registrado em relação aos efeitos das cianotoxinas ocorreu com a morte de 70 pessoas no município de Caruaru, estado de Pernambuco, durante tratamento de hemodiálise com a água contaminada com toxina de cianobactéria (Azevedo et al., 2002).

Como a prevenção de florações de cianobactérias envolve minimizar emissões de compostos nitrogenados e fosforados que muitas vezes são difusas, cabe aos processos convencionais de tratamento de água remover estes microrganismos e suas toxinas de modo a cumprir os padrões de potabilidade exigidos na legislação (Di Bernardo e Sabogal Paz, 2008).

As estações de tratamento de água para consumo humano em sua maioria são operadas com filtros de carvão ativado para eliminar gosto e odor da água, causados pelas cianobactérias, e também para reter suas toxinas (Di Bernardo e Sabogal Paz, 2008).

Devido ao maior custo do carvão ativado, e a disponibilidade do resíduo da produção de cana-de-açúcar no Brasil, um dos maiores produtores mundiais, a capacidade adsorvente do bagaço de cana-de-açúcar tem sido investigada como alternativa na remoção da microcistina da água (Jaguaribe et al., 2005; Albuquerque Jr. et al., 2008). Dentro deste contexto, neste trabalho é avaliada a eficiência do bagaço de cana-de-açúcar in natura em comparação ao carvão ativado na remoção de microcistina-LR de Microcystis aeruginosa.

\section{MATERIAIS E MÉTODOS}




\subsection{Preparação da amostra de toxina}

A amostra de toxina utilizada nos ensaios de adsorção foi proveniente de cultivo de Microcystis aeruginosa da cepa BB005, fornecida pelo Departamento de Botânica da Universidade Federal de São Carlos em março de 2011.

O cultivo foi realizado no Laboratório de Limnologia do Departamento Acadêmico de Química e Biologia da UTFPR - câmpus Curitiba, sede Ecoville, utilizando meio sintético de cultivo ASM-1, sendo que as principais condições para crescimento e manutenção do meio para a $M$. Aeruginosa foram: temperatura entre 22 e $28^{\circ} \mathrm{C}$; intensidade luminosa de $215 \mu \mathrm{mol} \mathrm{m} \mathrm{m}^{-2} \mathrm{~s}^{-1}$; fotoperíodo $12 / 12 \mathrm{~h}$ claro/h escuro e concentração inicial de $1,6.10^{3} \mathrm{cel} \mathrm{mL}^{-1}$ de acordo com procedimentos descrito por Jacinavicius et al. (2013).

A inoculação foi realizada na proporção de $10 \%$ de volume de inóculo para $100 \%$ de volume de meio de cultivo de acordo com procedimentos descritos por Jacinavicius et al. (2013).

A contagem de células foi realizada em hemacitômetro de Neubauer (profundidade 0,100 $\mathrm{mm}$ ) segundo metodologia proposta por Tortora et al. (2000), utilizando microscópio óptico Zeiss modelo Axiovert $40 \mathrm{C}$ até a verificação da concentração de $10^{6}$ cel $\mathrm{mL}^{-1}$.

Após ser quantificado, o cultivo foi colocado em um recipiente de 2,0 L de polietileno, homogeneizado, armazenado em freezer a aproximadamente $-8^{\circ} \mathrm{C}$, congelado e descongelado três vezes para rompimento da parede celular das cianobactérias e liberação da toxina para o meio de acordo com procedimento descrito por Jacinavicius et al. (2013).

Após este procedimento, uma amostra de $50 \mathrm{~mL}$ foi coletada para quantificação da toxina, e em seguida foram realizadas diluições do cultivo em água destilada para as concentrações de $2,36 \pm 0,34,3,33 \pm 0,25$ e $3,83 \pm 0,36 \mu \mathrm{g} \mathrm{L}^{-1}$ de toxina para posteriores ensaios de adsorção.

\subsection{Quantificação da toxina}

A quantificação da toxina do cultivo foi realizada no Laboratório do Centro de Análises e Ensaios Tecnológicos da TECPAR, Curitiba-PR, segundo metodologia descrita por Dahlmann e Luckas (2010), e analisada por Cromatografia Líquida de Alta Eficiência (Agilent 1100), acoplado a espectrômetro de massas triplo quadrupolo (Applied Biosystens API 4000) com fonte de ionização por electrospray.

A separação cromatográfica foi obtida em coluna analítica Eclipse XDB-C18 (4,6 x $150 \mathrm{~mm}, 5 \mu \mathrm{m}$, Agilent) e fase móvel constituída por: solvente A (10\% acetonitrila e $90 \%$ solução aquosa de acetato de amônia $5 \mathrm{mM}$ e ácido fórmico $1 \%)$ e solvente B $(90 \%$ acetonitrila e $10 \%$ solução aquosa de acetato de amônia $5 \mathrm{mM}$ e ácido fórmico $0,1 \%$ ), em eluição isocrática com $55 \%$ de A e $45 \%$ de B. O volume de injeção foi de $100 \mu \mathrm{L}$ e o limite de quantificação foi de $0,5 \mu \mathrm{g} \mathrm{L}^{-1}$.

\subsection{Preparo e caracterização dos materiais adsorventes}

O bagaço de cana-de-açúcar utilizado foi moído e seco em estufa a $100 \pm 10^{\circ} \mathrm{C}$ por $48 \mathrm{~h}$, triturado em liquidificador industrial por $5 \mathrm{~min}$ para posterior utilização nos ensaios de caracterização, conforme metodologia proposta por Belisário et al. (2011). Para o ensaio de adsorção foi utilizada a granulometria de 100 mesh de massa retida na peneira.

O carvão ativado utilizado (CAG) é de origem vegetal e composição granular, fabricado pela NORIT (modelo GAC 124W). Amostras de $10 \mathrm{~g}$ do carvão ativado foram colocadas em estufa a $60^{\circ} \mathrm{C}$ por $12 \mathrm{~h}$ e mantidas em dessecador. Para a caracterização, foram realizados os ensaios de granulometria segundo a NBR 11834:1991, e índice do número de iodo segundo NBR 12073:1991 (ABNT, 1991a; 1991b).

$\mathrm{O} \mathrm{pH}$ foi determinado em triplicata utilizando pHmetro pHTEK, modelo pHS-3E, conforme procedimentos descritos na norma ASTM D 3838-1980:1999 (ASTM, 1999). 
A microscopia eletrônica de varredura foi realizada em um microscópio Zeiss, modelo EVO/MAI 15 e em metalizador Quorum, modelo Q150RES.

A área superficial interna foi determinada por isotermas de adsorção/dessorção em $\mathrm{N}_{2}$ através do método Brunauer-Emmett-Teller (BET) no Instituto Lactec em um porosímetro Quantachrome, modelo NOVA1200.

\subsection{Isotermas de Adsorção}

Os ensaios de adsorção foram realizados no Laboratório de Saneamento do Departamento Acadêmico de Construção Civil da UTFPR, câmpus Curitiba, sede Ecoville, em uma incubadora Shaker da Solab, modelo SL 222, a temperatura controlada de $25 \pm 3^{\circ} \mathrm{C}$, agitação constante de $150 \mathrm{rpm}$, por $10 \mathrm{~h}$ com amostras em duplicata.

Foram utilizados erlenmeryes de $250 \mathrm{~mL}$, contendo $200 \mathrm{~mL}$ de solução de microcistina de 2,36 $\pm 0,34 \mu \mathrm{g} \mathrm{L}^{-1}, 3,33 \pm 0,25 \mu \mathrm{g} \mathrm{L}^{-1}$ e $3,83 \pm 0,36 \mu \mathrm{g} \mathrm{L}{ }^{-1}$ e $50 \mathrm{mg}$ de massa de material adsorvente para cada concentração.

Alíquotas de $10 \mathrm{~mL}$ das amostras do ensaio de adsorção foram coletadas em intervalos de duas horas, filtradas em membrana de acetato de celulose de $0,45 \mu \mathrm{m}$ e mantidas em recipientes de polietileno em refrigerador a $4^{\circ} \mathrm{C}$ para posterior quantificação da microcistinaLR.

A concentração da toxina adsorvida foi determinada utilizando a Equação (1).

$$
q_{e}=\frac{\left(C_{o}-C_{e}\right)}{M} \times V
$$

em que:

$q_{e}$ : é a concentração de equilíbrio da microcistina-LR em material adsorvente ( $\mu \mathrm{g}$ microcistina-LR $\mathrm{g}^{-1}$ de material adsorvente);

$C_{o}$ : é a concentração inicial de microcistina-LR ( $\mu$ g microcistina-LR $\mathrm{L}^{-1}$ de solução);

$C_{e}$ : é a concentração de equilíbrio de microcistina-LR ( $\mu \mathrm{g}$ microcistina-LR $\mathrm{L}^{-1} \mathrm{de}$ solução);

$V$ : é o volume da fase aquosa adicionada (L); e

$M$ : é a massa do material adsorvente $(\mathrm{g})$

A partir destes dados foram plotados gráficos da concentração de equilíbrio de microcistina-LR versus a quantidade adsorvida em $\mu \mathrm{g} \mathrm{g}^{-1}$ de material adsorvente e feito ajustes pelos modelos de Langmuir (Equação 2) e de Freundlich (Equação 3).

$$
q_{e}=\frac{q_{m a ́ x} \times b \times C_{e}}{1+b \times C_{e}}
$$

em que:

$q_{e}$ : é a concentração de equilíbrio de microcistina-LR em material adsorvente ( $\mu \mathrm{g}$ microcistina-LR $\mathrm{g}^{-1}$ de material adsorvente);

$q_{\text {máx }}$ : é a capacidade máxima de adsorção de microcistina-LR na monocamada do material adsorvente- limite de saturação ( $\mu \mathrm{g}$ microcistina-LR $\mathrm{g}^{-1}$ material adsorvente);

$C_{e}$ : é a concentração de equilíbrio de microcistina-LR ( $\mu \mathrm{g}$ microcistina-LR $\mathrm{L}^{-1} \mathrm{de}$ solução); e

$b$ : é a constante de equilíbrio da adsorção relacionada à energia de adsorção ( $\mathrm{L}$ de solução $\mu \mathrm{g}^{-1}$ de material adsorvente). 


$$
q_{e}=k C_{e^{\frac{1}{n}}}
$$

em que:

$q_{e}$ : é a concentração de equilíbrio de microcistina-LR em material adsorvente ( $\mu \mathrm{g}$ microcistina-LR $\mathrm{g}^{-1}$ de material adsorvente);

$k$ : é a constante da capacidade adsortiva ( $\mathrm{L}$ de solução $\mathrm{g}^{-1}$ de material adsorvente);

$C_{e}$ : é a concentração de equilíbrio de microcistina-LR ( $\mu \mathrm{g}$ microcistina-LR $\mathrm{L}^{-1} \mathrm{de}$ solução); e

$n$ : é a constante de equilíbrio da isoterma.

\section{RESULTADOS E DISCUSSÃO}

\subsection{Caracterização dos materiais adsorventes}

Os resultados da caracterização físico-química dos materiais adsorventes, bagaço de cana-de-açúcar e carvão ativado são apresentados na Tabela 1.

Tabela 1. Caracterização físico-química dos materiais adsorventes.

\begin{tabular}{lcc}
\hline \multicolumn{1}{c}{ Características } & Bagaço de cana-de-açúcar & Carvão Ativado \\
\hline Granulometria (\% massa) & 23,3 & 7,7 \\
$\mathrm{pH}$ & $4,1 \pm 0,05$ & $6,7 \pm 0,08$ \\
Área superficial interna $\left(\mathrm{m}^{2} \mathrm{~g}^{-1}\right)$ & 1,3 & 304,2 \\
Número de iodo $\left(\mathrm{mg} \mathrm{g}^{-1}\right)$ & nd & 665,86 \\
\hline
\end{tabular}

*nd: não determinado

A granulometria foi realizada para selecionar frações dos materiais adsorventes retidas na peneira com abertura nominal 100 mesh para o material adsorvente, que usualmente é o padrão utilizado no tratamento de água para consumo humano. Como o menor tamanho dos grãos do material adsorvente influencia na maior taxa de adsorção, é importante realizar este ensaio para conhecer o tempo requerido para o transporte do adsorvato nos poros do adsorvente (Di Bernardo e Sabogal, 2008).

$\mathrm{O} \mathrm{pH}$ do adsorvente é outro fator que influencia na adsorção, pois está diretamente relacionado à carga da superfície do adsorvente e ao grau de ionização dos solutos do adsorvato (Gonçalves et al., 2006). Huang et al. (2007) verificaram que o melhor adsorvente de microcistina-LR para três tipos de carvões ativados de origem vegetal, deve apresentar valor de $\mathrm{pH}$ menor no material adsorvente do que o da solução na qual a microcistina-LR está dissolvida. Sathishkumar et al. (2010) obtiveram melhor eficiência de retenção da microcistina-LR em pH de 3,0 no material adsorvente. De acordo com estes autores, o aumento do $\mathrm{pH}$ força as formas aniônicas da estrutura molecular da microcistina-LR, dificultando sua adsorção.

Além disso, a repulsão eletrostática entre os sítios vizinhos que causaria expulsão da microcistina-LR seria diminuída em menor $\mathrm{pH}$, aumentando as ligações de hidrogênio e a capacidade de adsorção. Os valores do $\mathrm{pH}$ do carvão ativado e do bagaço de cana-de-açúcar foram menores que 7,0, o que pode favorecer a adsorção da microcistina-LR de acordo com estudos previamente reportados.

A baixa área superficial do bagaço de cana-de-açúcar também foi verificada por Belisário et al. (2011) $\left(1,49 \mathrm{~m}^{2} \mathrm{~g}^{-1}\right)$ que atribuíram o potencial adsortivo à formação de monocamadas de paracetamol na superfície deste material devido à presença de grupos funcionais variados. Isto porque este adsorvente é um biopolímero natural constituído principalmente de celulose 
(50\%), hemicelulose (25\%) e lignina (25\%) de acordo com Meza et al. (2006). Assim como evidenciado por Albuquerque Jr. et al. (2008), não foi possível obter o número de iodo do bagaço de cana-de-açúcar por meio da norma de caracterização dos carvões ativados, provavelmente devido à reduzida área superficial.

De acordo com Müller et al. (2009), o número de iodo é um indicador de volume de microporos, e a remoção da microcistina-LR é influenciada pelo volume dos microporos secundários e mesoporos do carvão ativado, que não foram determinados neste trabalho.

Neste estudo foram verificados valores do número de iodo e da área superficial inferiores aos valores reportados por Donati et al. (1994) de 964 e $953 \mathrm{mg} \mathrm{g}^{-1}$ e de 1.196 e $1.366 \mathrm{~m}^{2} \mathrm{~g}^{-1}$, respectivamente, para carvões ativados de origem vegetal, o que pode ter influenciado na diminuição da remoção devido a maior concentração da microcistina-LR na solução.

\subsubsection{Análises do bagaço de cana-de-açúcar e do carvão ativado por MEV}

$\mathrm{Na}$ Figura 1 são apresentadas as fotomicrografias da superfície dos materiais adsorventes utilizados nos ensaios de adsorção.

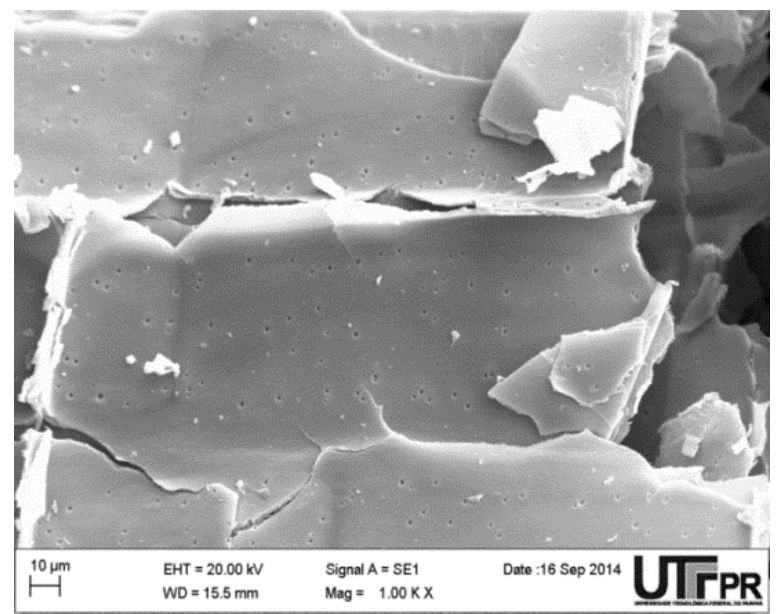

a)

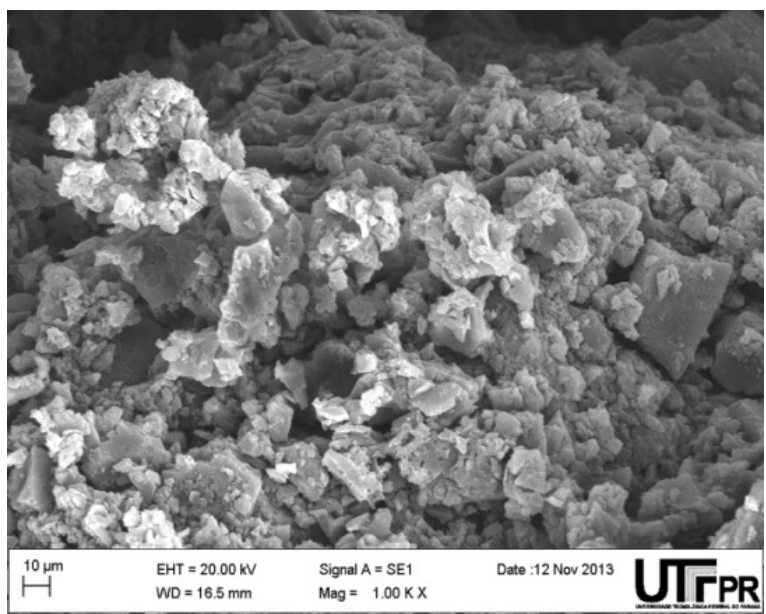

b)

Figura 1. Fotomicrografias eletrônicas de varredura da superfície do: a) bagaço de cana-de-açúcar com aproximação de 1,0 kX; b) carvão ativado com aproximação de 1,0 kX.

As imagens obtidas por MEV revelam que a superfície do bagaço de cana-de-açúcar apresenta-se lisa e com poros praticamente homogêneos e simétricos (macroporos) (Figura 1a); e a superfície do carvão ativado apresenta porosidade heterogênea com poros difusos (microporos), caracterizando sua maior área superficial (Figura 1b). Fotomicrografias similares foram verificadas por Belisário et al. (2011) para superfície do bagaço de cana-deaçúcar.

\subsubsection{Avaliação da remoção da microcistina-LR}

A variação da remoção da microcistina-LR em função do tempo de adsorção $(h)$ para os ensaios de adsorção com concentrações de $2,36 \pm 0,34 \mu \mathrm{g} \mathrm{L} \mathrm{L}^{-1}, 3,33 \pm 0,25 \mu \mathrm{g} \mathrm{L^{-1 }}$ e $3,83 \pm 0,36 \mu \mathrm{g} \mathrm{L}^{-1}$ é apresentada na Figura 2. 


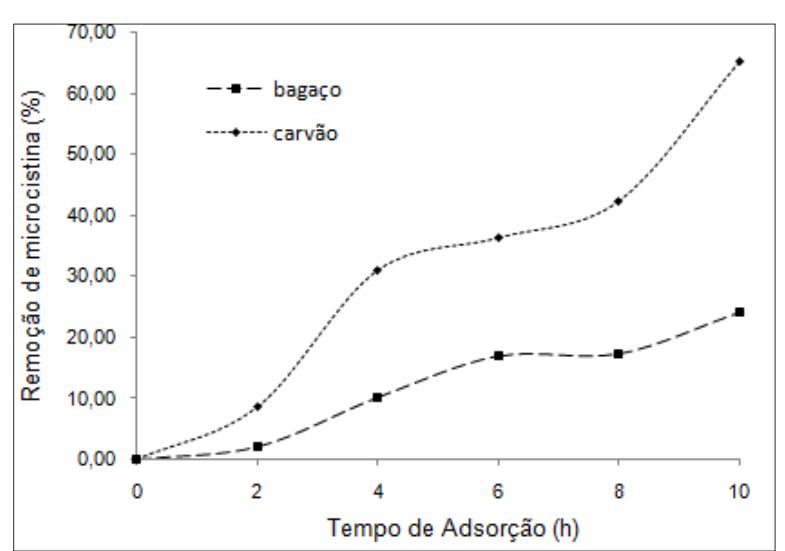

a) Amostra com concentração de $2,36 \mu \mathrm{g} \mathrm{L} \mathrm{L}^{-1}$

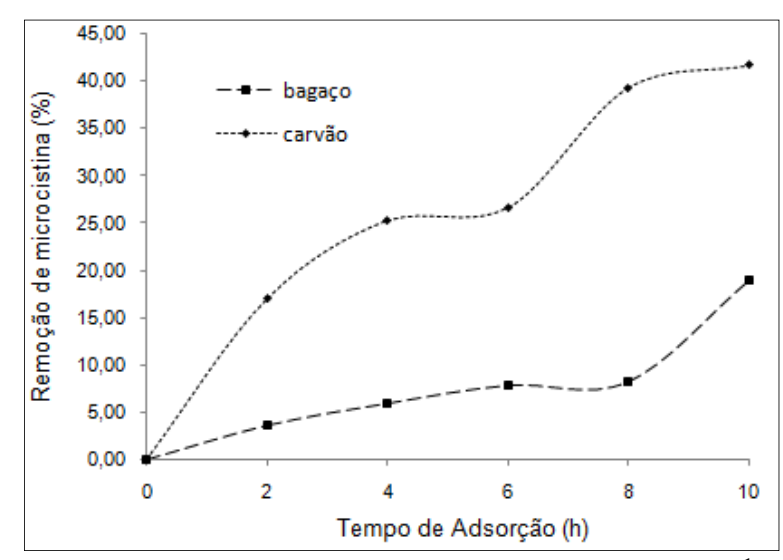

b) Amostra com concentração de $3,33 \mu \mathrm{g} \mathrm{L}{ }^{-1}$

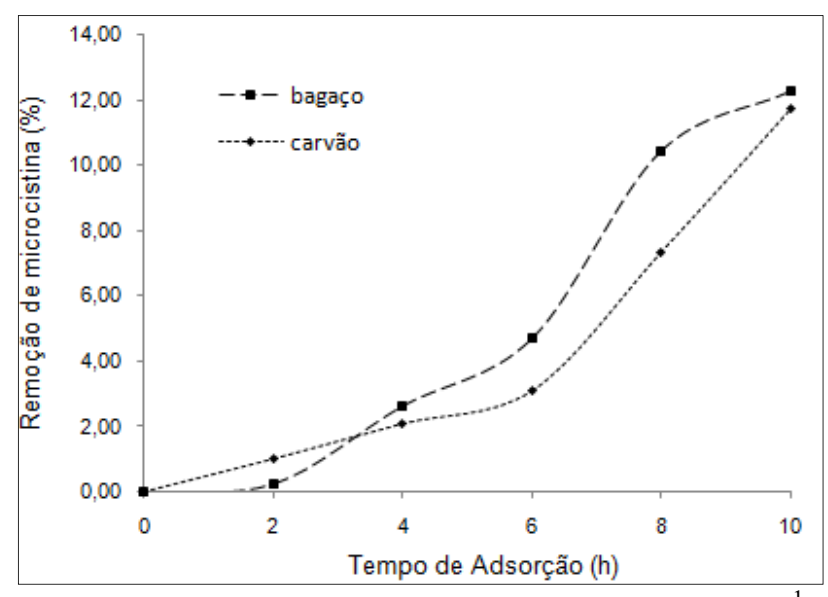

c) Amostra com concentração de $3,83 \mu \mathrm{g} \mathrm{L}{ }^{-1}$

Figura 2.Variação da retenção da microcistina-LR no intervalo de tempo de $10 \mathrm{~h}$ de adsorção.

As maiores eficiências de retenção foram observadas para o carvão ativado e podem ser justificadas em função da maior área superficial e do número de iodo em relação àquelas verificadas para o bagaço de cana-de-açúcar, independente da concentração de microcistinaLR na solução inicial.

As eficiências médias de retenção da toxina resultaram em 65,25; 41,74 e 11,75\% no carvão ativado e de 24,$15 ; 18,92$ e $12,27 \%$ no bagaço de cana-de-açúcar para as concentrações de 2,36, 3,33 e 3,83 $\mu \mathrm{g} \mathrm{L}^{-1}$, respectivamente. É possível notar tendência de similaridade da eficiência de retenção dos materiais em função do aumento da concentração da toxina para $3,83 \mu \mathrm{g} \mathrm{L}^{-1}$ nas seis primeiras horas dos ensaios, de $12,27 \%$ e $11,75 \%$ para o bagaço de cana-de-açúcar e carvão ativado, respectivamente.

Pyo e Moon (2005) obtiveram retenção da microcistina-LR de 39\% com concentração inicial de $1000 \mu \mathrm{g} \mathrm{L}^{-1}$ em carvão ativado com área superficial de $750 \mathrm{~m}^{2} \mathrm{~g}^{-1}$ e número de iodo de $1000 \mathrm{mg} \mathrm{g}^{-1}$. A menor retenção desta toxina neste trabalho indica que as características morfológicas deste carvão ativado não eram específicas para retenção desta toxina.

Belisário et al. (2011) obtiveram menor eficiência de retenção para paracetamol (23\%) sem qualquer ativação do bagaço de cana-de-açúcar. No entanto, Molica et al. (2013) justificaram a maior eficiência de retenção da microcistina-LR de até $70 \%$ devido ao aumento da área superficial do bagaço de cana-de-açúcar pela ativação física.

\subsubsection{Isotermas de adsorção}

As isotermas de adsorção de Langmuir e Freundlich, obtidas através da linearização dos dados experimentais utilizando as Equações (2) e (3) para obtenção das constantes e dos 
respectivos coeficientes de determinação $\left(\mathrm{r}^{2}\right)$, são apresentadas na Tabela 2.

Tabela 2. Resumo do ajuste dos parâmetros das isotermas de adsorção para o modelo de Langmuir e de Freundlich e do coeficiente de determinação $\left(\mathrm{r}^{2}\right)$

\begin{tabular}{|c|c|c|c|c|c|c|c|}
\hline \multicolumn{2}{|l|}{ Isoterma } & \multicolumn{3}{|c|}{ Langmuir } & \multicolumn{3}{|c|}{ Freundlich } \\
\hline Material adsorvente & $\begin{array}{c}C_{o} \\
\left(\mu g L^{-1}\right)\end{array}$ & $\underset{\left(\mu g^{-1}\right)}{\mathbf{q}_{\text {máx }}}$ & $\begin{array}{c}b \\
\left(L^{-1} g^{-1}\right)\end{array}$ & $\mathbf{r}^{2}$ & $\begin{array}{c}k \\
\left(\mu g^{-1}\right)\end{array}$ & $\mathbf{n}$ & $\mathbf{r}^{2}$ \\
\hline Bagaço de cana-de-açúcar & 236 & 49,26 & 5,49 & 0,94 & 962,72 & 1,66 & 0,94 \\
\hline Carvão ativado & 2,56 & 47,17 & 1,37 & 0,94 & 338,61 & 1,57 & 0,93 \\
\hline Bagaço de cana-de-açúcar & 333 & $-333,33$ & $-0,40$ & 0,95 & 214,44 & 1,06 & 0,84 \\
\hline Carvão ativado & & $-40,82$ & $-0,45$ & 0,93 & 0,83 & 0,65 & 0,93 \\
\hline Bagaço de cana-de-açúcar & 383 & 68,03 & 29,40 & 0,93 & 6047,84 & 2,37 & 0,98 \\
\hline Carvão ativado & J, J & 217,40 & 2,30 & 0,97 & 2154,27 & 1,59 & 0,91 \\
\hline
\end{tabular}

A capacidade de adsorção com melhor ajuste linear para isoterma de Langmuir foi obtida para o carvão ativado utilizando amostra com maior concentração de microcistina-LR com coeficiente de determinação $\left(\mathrm{r}^{2}\right)$ de 0,97 e $\mathrm{q}_{\text {máx }}$ de $217,40 \mu \mathrm{g} \mathrm{g}^{-1}$. Para o bagaço de cana-de-açúcar o melhor ajuste foi observado para a amostra com menor concentração de microcistina-LR com $\mathrm{r}^{2}$ de 0,94 e $\mathrm{q}_{\text {máx }}$ de 49,26 $\mu \mathrm{g} \mathrm{g}^{-1}$ (Tabela 2).

A capacidade máxima de adsorção e a constante de adsorção da isoterma de Langmuir para a amostra com concentração de $3,33 \mu \mathrm{g} \mathrm{L} \mathrm{L}^{-1}$ resultaram em valores negativos para os materiais, indicando a não representatividade deste modelo quanto à capacidade de adsorção para esta concentração.

A capacidade de adsorção com melhor ajuste linear para a isoterma de Freundlich foi obtida para o bagaço de cana-de-açúcar para a amostra com maior concentração de microcistina-LR com $\mathrm{r}^{2}$ de $0,98 \mathrm{e} \mathrm{k}$ de $6047,84 \mu \mathrm{g} \mathrm{g}^{-1}$. Para o carvão ativado o melhor ajuste foi observado para as amostras com concentração de 2,36 e $3,33 \mu \mathrm{g} \mathrm{L}^{-1} \mathrm{com} \mathrm{r}^{2}$ de $0,93, \mathrm{k}$ de $338,61 \mu \mathrm{g} \mathrm{g}^{-1}$ e k de $0,83 \mu \mathrm{g} \mathrm{g}^{-1}$, respectivamente. Porém para esta última amostra o valor de $\mathrm{n}$ resultou inferior a $1(0,65)$, indicando que a adsorção também não foi favorável segundo Bulut e Aydin (2006).

A constante $n$ está relacionada com a força de ligação entre o adsorvente e a microcistina-LR e a constante $\mathrm{k}$ à capacidade do adsorvente em reter a microcistina-LR. $\mathrm{O}$ bagaço de cana-de-açúcar apresentou a maior capacidade adsortiva à microcistina-LR $(\mathrm{k}=6047,84)$ e elevado valor de $\mathrm{n}(2,37)$, correspondendo a maior irreversibilidade do

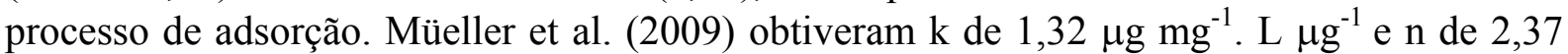
para carvão ativado de madeira na retenção de microcistina aeruginosa.

Para as demais amostras, os valores de $n$ variaram entre 1 e 10 , indicando que a adsorção foi favorável.

\section{CONCLUSÃO}

Com base na obtenção e na análise dos resultados, pode-se chegar as seguintes conclusões:

$\mathrm{O}$ bagaço de cana-de-açúcar apresentou área superficial interna de $1,3 \mathrm{~m}^{2} \mathrm{~g}^{-1}$, enquanto que o carvão ativado granular apresentou área superficial interna de $304,2 \mathrm{~m}^{2} \mathrm{~g}^{-1}$ e número de iodo de $665,86 \mathrm{mg} \mathrm{g}^{-1}$.

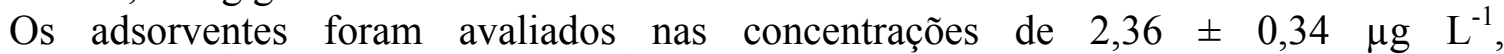
$3,33 \pm 0,25 \mu \mathrm{g} \mathrm{L}^{-1}$ e $3,83 \pm 0,36 \mu \mathrm{g} \mathrm{L}^{-1}$ e obtiveram melhor performance de retenção da Microcistina-LR de $65 \%$ para o carvão ativado granular e de $24 \%$ para o bagaço de cana-de- 
açúcar na concentração de $2,36 \pm 0,34 \mu \mathrm{g} \mathrm{L}{ }^{-1}$.

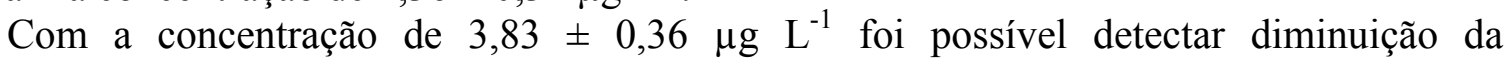
performance de retenção da Microcistina-LR para o carvão ativado granular (11,75\%) e para o bagaço de cana-de-açúcar (12,35\%). Nesta condição, foi possível constatar o potencial adsorvente do bagaço de cana-de-açúcar.

A capacidade de adsorção com melhor ajuste linear para isoterma de Langmuir foi obtida para o carvão ativado utilizando amostra com maior concentração de Microcistina-LR. Para o bagaço de cana-de-açúcar o melhor ajuste foi observado para a amostra com menor concentração de Microcistina-LR.

A capacidade de adsorção com melhor ajuste linear para a isoterma de Freundlich foi obtida para o bagaço de cana-de-açúcar para a amostra com maior concentração de microcistina-LR com r ${ }^{2}$ de 0,98 e $\mathrm{k}$ de $6047,84 \mu \mathrm{g} \mathrm{g}^{-1}$. Para o carvão ativado, o melhor ajuste foi observado para as amostras com menor concentração com $\mathrm{r}^{2}$ de $0,93 \mathrm{e} \mathrm{k} \mathrm{de} 338,61 \mu \mathrm{g} \mathrm{g}^{-1}$.

\section{AGRADECIMENTOS}

Os autores agradecem à equipe do Laboratório de Tecnologias Ambientais e Agronômicas do Instituto de Tecnologia do Paraná pelas análises quantitativas das toxinas da cianobactéria.

\section{REFERÊNCIAS}

ALBUQUERQUE JR., E. C.; MÉNDEZ, M. O. A.; COUTINHO, A. R.; FRANCO, T. T. Removal of cyanobacteria toxins from drinking water by adsorption on activated carbon fibers. Materials Research, v. 11, n. 3, p. 371- 380, 2008. http://dx.doi.org/10.1590/S1516-14392008000300023

ASSOCIAÇÃO BRASILEIRA DE NORMAS TÉCNICAS - ABNT. NBR 11834:1991. Carvão ativado pulverizado para tratamento de água - especificação. Rio de Janeiro, 1991a

ASSOCIAÇÃO BRASILEIRA DE NORMAS TÉCNICAS - ABNT. NBR 12073:1991. Carvão ativado pulverizado- Determinação do número de iodo. Rio de Janeiro, $1991 \mathrm{~b}$.

AMERICAN SOCIETY OF TESTING AND MATERIAL - ASTM. D 3838-1980:1999. Standard Test Method for $\mathrm{pH}$ of Activated Carbon. West Conshohocken, 1999.

AZEVEDO, S. M. F. O.; CARMICHAEL, W. W.; JOCHIMSEN, E. M.; RINEHART, K. L.; LAU, S.; SHAW, G. R. et al. Human in toxication by microcystins during renal dialysis treatment in Caruaru-Brazil. Toxicology, v. 181-182, p. 441-446, 2002. http://dx.doi.org/10.1016/S0300-483X(02)00491-2

BELISÁRIO, M.; GALAZZI, R. M.; BALTHAZAR, D. C.; PEREIRA, M. G.; RIBEIRO, A. V. F. N.; RIBEIRO, J. N. Emprego de resíduo de bagaço de cana de açúcar descartado por usinas de álcool como agente removedor de paracetamol em meio aquoso sob agitação. Revista Analytica, n. 50, p. 54- 62, 2011.

BRASIL. Ministério da Saúde. Secretaria de Vigilância em Saúde. Portaria $n^{0}$ 2914, de 12 de dezembro de 2011. Dispõe sobre os procedimentos de controle e de vigilância da qualidade da água para consumo humano e seu padrão de potabilidade. Diário Oficial [da] União, Brasília, DF, Seção 1, 14 dez. 2011. 
BULUT, Y.; AYDIN, H. A. Kinetics and thermodynamics study of methylene blue adsorption on wheat shells. Desalination, v. 194, p. 259-267, 2006. http://dx.doi.org/10.1016/j.desal.2005.10.032

DI BERNARDO, L.; SABOGAL PAZ, L. P. S. Seleção de tecnologias de tratamento de água. São Carlos: LDIBE, 2008. 878 p.

DAHLMANN, J.; LUCKAS, B. Analysis of selected microcystins in drinking and surface water using a highly sensitive direct injection technique. AB Sciex, n. 1830410-01, 2010 .

DONATI, C.; DRIKAS, M.; HAYES, R.; NEWCOBE, G. Microcystin-LR adsorption by powdered activate carbon. Water Research, v. 28, n.8, p. 1735-1742, 1994. http://dx.doi.org/10.1016/0043-1354(94)90245-3

GONÇALVES, G. C.; MENDES, E. S.; PEREIRA, N. C.; SOUSA, J. C. Produção de carvão ativado a partir de bagaço e melaço de cana-de-açúcar. Acta Scientiarum Technology, v. 28, n. 1, p. 21-27, 2006. http://dx.doi.org/10.4025/actascitechnol.v28i1.1203

HUANG, W. J.; CHENG, B. L.; CHENG, Y. L. Adsorption of microcystin-LR by three types of activated carbon. Journal of Hazardous Materials,v. 141, p. 115-122, 2007.

JACINAVICIUS, F. R.; GAMA JUNIOR, W. A.; AZEVEDO, M. T. P; SANT`ANNA, C. L. Manual para cultivo de cianobactérias. São Paulo: Secretaria do Meio Ambiente, 2013.

JAGUARIBE, E. F.; MEDEIROS, L. L.; BARRETO, M. C. S.; ARAUJO, L. P. The performance of activated carbons from sugarcane bagasse, babassu, and coconut shells in removing residual chlorine. Brazilian Journal of Chemical Engineering, v. 22, n. 01, p. 41-47, 2005. http://dx.doi.org/10.1590/S0104-66322005000100005

MEZA, J. C.; SIGOllot, J. C.; LOMASCOlO, A.; NAVARRO, D.; AURIA, R. New Process for Fungal Delignification of Sugar-Cane Bagasse and Simultaneous Production of Laccase in a Vapor Phase Bioreactor. Journal of Agricultural. Food Chemistry, v. 54, p. 3852-3858, 2006. http://dx.doi.org/10.1021/jf053057j

MOLICA, R. J. R.; DUARTE, M. M. B.; AVELAR, F. P.; LIMA FILHO, N. M.; NEVES, C. C. L.; BARAÚNA, O. S. et al. Adsorção de cianotoxinas em diferentes matrizes. In: FUNDAÇÃO NACIONAL DE SAÚDE. $5^{\circ}$ Caderno de Pesquisa em Engenharia de Saúde Pública. 2. ed. Brasília, 2013. p. 63-95.

MÜLLER, C. C.; RAYA-RODRIGUEZ, M. T.; CYBIS, L. F. Adsorção em carvão ativado em pó para remoção de microcistina de água de abastecimento público. Engenharia Sanitária e Ambiental, v. 14, n. 1, p. 29-38, 2009. http://dx.doi.org/10.1590/S141341522009000100004

PYO, D.; MOON, D. Adsorption of Microcystin LR by activated carbon fibers. Bulletin of the Korean Chemical Society, v. 26, n. 12, p. 2089-2092, 2005.

SATHISHKUMAR, M.; PAVAGADHI, S.; VIJAYARAGHAVAN, K.; BALASUBRAMANIAN, R.; ONG, S.L. Experimental studies on removal of microcystin-LR by peat. Journal of Hazardous Materials, v. 184, p. 417-424, 2010. http://dx.doi.org/10.1016/j.jhazmat.2010.08.051

TORTORA, G. J.; FUNKE, B. R.; CASE C. L. Microbiologia. 6. ed. Porto Alegre: Artmed, 2000 . 